\title{
Laxative use and clinical correlates in hospitalized patients with obsessive-compulsive disorder: a retrospective descriptive study
}

This article was published in the following Dove Press journal: Neuropsychiatric Disease and Treatment

\author{
Jianbo Lai ${ }^{1-3, *}$ \\ Weihua Zhou ${ }^{1-3, *}$ \\ Qiaoqiao Lu' \\ Tingting Huang' \\ Yi $\mathrm{Xu}^{1-3}$ \\ Shaohua $\mathrm{Hu}^{1-3}$ \\ 'Department of Psychiatry, First \\ Affiliated Hospital, Zhejiang University \\ School of Medicine, Hangzhou, \\ People's Republic of China; ${ }^{2}$ The Key \\ Laboratory of Mental Disorder's \\ Management in Zhejiang Province, \\ Hangzhou, People's Republic of China; \\ ${ }^{3}$ Brain Research Institute of Zhejiang \\ University, Hangzhou, People's \\ Republic of China \\ *These authors contributed equally \\ to this work
}

Background: Constipation is a common clinical problem with insufficient attention. Medication-emergent constipation is a rarely studied adverse reaction in patients with obsessivecompulsive disorder (OCD).

Methods: In this descriptive study, we retrospectively investigated the prevalence of laxative use and its relationship with clinical characteristics in hospitalized OCD patients. A total of 51 OCD patients were included in the final analysis.

Results: The proportion of patients using laxatives was $31.4 \%$, and the commonly used laxatives were phenolphthalein tablet, lactulose and congrongtongbian oral liquid (a patent herbal medicine). In the laxative group, hospital stays were longer when compared to the nonlaxative group. Moreover, the dose of paroxetine was higher in patients treated with laxatives than in those without laxative use. Correlation analysis indicated that laxative use was positively associated with hospital stays, as well as the dose of paroxetine.

Conclusion: The current study provided a preliminary picture of constipation and laxative use in hospitalized OCD patients. Close monitoring and treatment of constipation are recommended in OCD patients with pharmacotherapy.

Keywords: obsessive-compulsive disorder, constipation, laxative, hospital stay, paroxetine

\section{Introduction}

Constipation is one of the common gastrointestinal complaints in clinical practice and afflicts appropriately $0.7 \%-79 \%$ (median value $16 \%$ ) of the general population. Generally, constipation refers to restricted bowel movement and less evacuation of feces. ${ }^{2}$ Numerous factors may contribute to constipation, including mechanic, endocrine, metabolic, neurologic, psychogenic, iatrogenic and other miscellaneous conditions. ${ }^{1-4}$ Prescription of laxatives is prevalent in physician visits for constipation. ${ }^{4}$

Among the iatrogenic conditions, medication-associated constipation in patients with mental disorders is not uncommon. Antidepressants, antipsychotics and anticonvulsants are all involved in the presence of secondary constipation in this population. ${ }^{4-6}$ Constipation causes extra expenditure for laxatives and medical examinations, weakens life quality and even diminishes therapeutic adherence. ${ }^{4}$ However, little attention is proactively delivered to recognize and monitor this condition in medicated mentally ill patients.

Obsessive-compulsive disorder (OCD) is featured by recurrent, time-consuming, self-generating obsessions and compulsions, which are difficult to resist and can lead to significant distress or impairment in most cases. ${ }^{7,8}$ According to various studies, selective serotonin reuptake inhibitors (SSRIs) are currently the major pharmacological management of treating OCD. ${ }^{7,9}$ It was reported that appropriately half of the OCD
Correspondence: Shaohua Hu Department of Psychiatry, First Affiliated Hospital, Zhejiang University School of Medicine, 79 Qingchun Road, Hangzhou 310003, People's Republic of China Tel/fax +86 57l 87235948

Email dorhushaohua@zju.edu.cn 
patients achieved remission following SSRI treatment. ${ }^{10}$ In addition, antipsychotics have been recently recognized as augmentation strategies in SSRI-refractory OCD patients. ${ }^{7,9}$ However, awareness of medication-associated adverse reactions, such as constipation, is inadequate in practice. The consequence following delayed detection and treatment of constipation in medicated OCD patients is rarely studied.

Therefore, focusing on the constipation problem in medicated OCD patients is of great importance from a clinical standpoint. The aim of this study was to retrospectively investigate the prevalence and clinical correlates of laxative consumption in hospitalized OCD patients.

\section{Methods}

This retrospective study enrolled hospitalized individuals from January 2011 to May 2017 in the Mental Health Center, First Affiliated Hospital, Zhejiang University School of Medicine. The diagnosis of OCD was made according to the Diagnostic and Statistical Manual of Mental Disorders, fourth edition. Owing to the retrospective, noninterventional nature of the current study, and anonymous information collection, informed consent was waived, which was approved by the institutional review board of the First Affiliated Hospital, Zhejiang University School of Medicine. The defecation situation of all patients was evaluated and recorded in the electronic medical system. All data in this study were extracted from the electronic medical records by two independent researchers (QQL and TTH). Any disagreement was resolved by rechecking the medical records or discussing with a third evaluator (WHZ). The subjects fulfilling the following criteria were included: 1) 16-60 years old; 2) free of constipation on admission and in the first week of hospitalization; 3) no prophylactic use of laxative prior to or during hospitalization; 4) no accompanying severe physical disorders and irritable bowel syndrome; 5) good compliance to treatment and hospital stays $>1$ week; and 6) well tolerance to pharmacological agents and no severe adverse events reported. In this study, daily administration of laxative use after hospitalization was considered as a proxy for the emergence of constipation.

Patients with a primary diagnosis and discharge diagnosis of OCD were screened by the electronic medical system and then manually reviewed of each admission. Demographic and clinical profiles, such as age, gender, education, marriage, duration of disease, medication history before hospitalization, the score of Yale-Brown Obsessive-Compulsive Scale (Y-BOCS) on admission, ${ }^{11}$ medication prescribed by hospital discharge, laxative use and comorbid psychiatric or other conditions, were collected in the present study.
Data analysis was conducted using Statistical Package for the Social Sciences (SPSS) Statistics for Windows, version 16.0 (SPSS Inc., Chicago, IL, USA). All participants were accordingly divided into two groups, the laxative group and the nonlaxative group. The categorical variables were analyzed by the chi-square test. When the continuous variables (education years, age, illness duration, hospital stays, Y-BOCS score and medication doses) were not qualified for normal distribution, they were analyzed with nonparametric testing (Mann-Whitney) or, otherwise, independent $t$-test was used. Spearman's correlation analysis was performed between laxative use and other clinical profiles. $p<0.05$ (two tailed) was considered as statistically significant.

\section{Results}

\section{Sample characteristics}

Totally, 51 patients diagnosed with OCD were eligible in this study (16 [31.4\%] patients in the laxative group and 35 [68.6\%] patients in the nonlaxative group). In the laxative group, three patients were diagnosed with comorbid bipolar disorder. The commonly used laxatives were phenolphthalein tablet, lactulose and congrongtongbian oral liquid (a patent herbal medicine). In the nonlaxative group, two patients were identified with comorbid bipolar disorder and two with major depressive disorder. These two groups did not differ in terms of age, gender, marital status, education years, duration of illness or Y-BOCS scores (Table 1). Of note, the hospital stays (days) were longer in the laxative group when compared with the nonlaxative group (34.1 \pm 18.4 vs $22.6 \pm 9.82, p=0.02$ ).

\section{Medications}

In the laxative group, six patients had taken medications before hospitalization, and the number of medicated patients

Table I Demographic and partial clinical profiles of the patients

\begin{tabular}{|c|c|c|c|}
\hline Variables & $\begin{array}{l}\text { Laxative } \\
\text { group } \\
(n=16)\end{array}$ & $\begin{array}{l}\text { Nonlaxative } \\
\text { group } \\
(\mathrm{n}=\mathbf{3 5})\end{array}$ & p-value* \\
\hline Gender (male/female) & $10 / 6$ & $21 / 14$ & 0.87 \\
\hline $\begin{array}{l}\text { Marital status } \\
\text { (married/unmarried) }\end{array}$ & $7 / 9$ & $13 / 22$ & 0.65 \\
\hline Education (years, mean $\pm S D$ ) & $11.7 \pm 2.91$ & $12.0 \pm 3.24$ & 0.86 \\
\hline Age (years, mean $\pm S D$ ) & $29.5 \pm 13.4$ & $28.1 \pm 11.8$ & 0.72 \\
\hline $\begin{array}{l}\text { Duration of illness } \\
\text { (years, mean } \pm S D \text { ) }\end{array}$ & $4.49 \pm 3.80$ & $3.83 \pm 3.31$ & 0.53 \\
\hline $\begin{array}{l}\text { Hospital stays } \\
(\text { days, mean } \pm S D)\end{array}$ & $34.1 \pm 18.4$ & $22.6 \pm 9.82$ & 0.02 \\
\hline Y-BOCS score $($ mean \pm SD) & $23.9 \pm 6.38$ & $23.2 \pm 4.92$ & 0.50 \\
\hline
\end{tabular}

Note: *Mann-Whitney testing for continuous variables, significance at $p<0.05$ (two tailed).

Abbreviations: SD, standard deviation; Y-BOCS, Yale-Brown ObsessiveCompulsive Scale. 
Table 2 Medications used to treat the patients during hospitalization

\begin{tabular}{|c|c|c|c|}
\hline Medications & $\begin{array}{l}\text { Laxative } \\
\text { group } \\
(n=16)\end{array}$ & $\begin{array}{l}\text { Nonlaxative } \\
\text { group } \\
(n=35)\end{array}$ & p-value* \\
\hline \multicolumn{4}{|l|}{ Paroxetine } \\
\hline Patients, n (\%) & $7(43.7)$ & $10(28.6)$ & - \\
\hline Dose $(\mathrm{mg})$, mean $\pm \mathrm{SD}$ & $67.1 \pm 11.1$ & $54.0 \pm 9.66$ & 0.03 \\
\hline \multicolumn{4}{|l|}{ Sertraline } \\
\hline Patients, n (\%) & $3(18.7)$ & $12(34.3)$ & - \\
\hline Dose $(\mathrm{mg})$, mean $\pm S D$ & $200 \pm 0$ & $167 \pm 45.6$ & 0.14 \\
\hline \multicolumn{4}{|l|}{ Fluvoxamine } \\
\hline Patients, n (\%) & $4(25.0)$ & $7(20.0)$ & - \\
\hline Dose $(\mathrm{mg})$, mean $\pm S D$ & $200 \pm 70.7$ & $229 \pm 80.9$ & 0.56 \\
\hline \multicolumn{4}{|l|}{ Quetiapine } \\
\hline Patients, n (\%) & $8(50.0)$ & $12(34.3)$ & - \\
\hline Dose $(\mathrm{mg})$, mean $\pm \mathrm{SD}$ & $312 \pm 223$ & $229 \pm 80.9$ & 0.12 \\
\hline
\end{tabular}

Note: *Mann-Whitney testing for continuous variables, significance at $p<0.05$ (two tailed).

Abbreviation: SD, standard deviation.

was 13 in the nonlaxative group. The proportion of OCD patients treated with medications prior to admission did not differ between the two groups. In the two groups, most patients were prescribed with a combination of certain SSRI and typical antipsychotic. The medications used during hospital discharge are listed in Table 2. The dose of paroxetine was significantly higher in the laxative group when compared to the nonlaxative group $(67.1 \pm 11.1 \mathrm{vs}$ $54.0 \pm 9.66, p=0.03)$. No significant difference was revealed in the dose of sertraline, fluvoxamine or quetiapine between the two groups. In addition to the aforementioned drugs, other antidepressants (fluoxetine, duloxetine and venlafaxine), antipsychotics (aripiprazole, risperidone, olanzapine and paliperidone) and anticonvulsants (valproate) were also used in the minority of OCD patients.

\section{Correlation analysis}

Laxative use was positively associated with hospital stays ( $\rho=0.339, p=0.015)$ and the dose of paroxetine ( $\rho=0.542$, $p=0.025)$. No significant association was demonstrated between laxative use and other indexes (eg, age, education years, duration of illness, Y-BOCS score and doses of sertraline, fluvoxamine or quetiapine).

\section{Discussion}

Medication-emergent constipation is a particular problem in hospitalized OCD patients. The current study offers further insights into the prevalence of constipation and laxative use in this population. Laxative use was associated with longer hospital stays, extra economic burden and pharmacological therapy. To the best of our knowledge, this is the first clinical research focusing on the laxative use in hospitalized OCD patients.

In this study, nearly one-third of the patients used laxatives and responded well to laxative supplement. None of these patients changed their main medications because of constipation. Given the underreporting cases, the current situation of medication-induced constipation was challenging. Therefore, active assessment before initiating pharmacotherapy and close monitoring when taking medications seem to be necessary in OCD patients.

Several steps/evaluations are needed before prescribing medications. First, evaluate the past experience of constipation, dietary structure, physical activity, fluid intake and tolerability to previous medications. Second, choose a particular anti-OCD drug based on the foregoing information. In our study, doses of paroxetine were positively associated with laxative use. Therefore, for patients who have a high propensity to develop constipation, assigning an alternative SSRI other than paroxetine seems to be a better choice. Drugs that have a potent anticholinergic activity should be avoided. Third, address the risk of constipation and encourage the patient to report any discomfort after taking medications. At last, inform the patient to eat more fruit, do more exercise and take more water. When pharmacotherapy initiates, daily inquiry and record of defecation is necessary. Although no association between medication doses and laxative use was identified in this study except paroxetine, special attention is still needed in clinical practice when the dose of other medications is escalated up to the therapeutic dose. Furthermore, continuous monitoring is also warranted after hospital discharge if the constipation condition runs a chronic course.

The current study is a preliminary investigation, and many questions need to be clarified in future research, which are as follows: 1) Most individuals in the laxative group treated with a combination of an SSRI and an antipsychotic, would this treatment strategy have a higher risk of developing constipation than monotherapy? 2) Although some patients were treated with a high dose of anti-OCD medications, no constipation was reported after taking these agents. Therefore, some protective determinants for constipation, such as the specific constitution of gut microbiome, may exist in these patients. ${ }^{12} 3$ ) How to design an individualized pharmacologic strategy to lower the risk of developing constipation? Thus, a comprehensive assessment of the likelihood of constipation is needed before prescribing any anti-OCD agent.

Several limitations of this study were needed to be clarified. First, the number of OCD patients included was only 51 , with the number of patients in the laxative group 16 . 
The small sample size may weaken the statistical power. Second, the influence of diet, exercise and fluid intake on evacuation was not evaluated in this study. Third, adjusting the dose of the existing drugs or addition of new drugs was necessary according to the therapeutic response. However, the effects of these factors on the bowel motility were also not evaluated. Lastly, the number of patients who received the anticonvulsant (valproate), antidepressants (fluoxetine, duloxetine and venlafaxine) or antipsychotics (aripiprazole, risperidone, olanzapine and paliperidone) was too small to analyze their influence on the bowel movements.

\section{Conclusion}

This brief study from a clinical perspective demonstrates the high prevalence of laxative use and its relationship to clinical characteristics in medicated OCD patients. More attention is necessary to be delivered to this topic, and more determinants of constipation should be identified in the future.

\section{Acknowledgments}

This work was supported by the grants of the Project of Health Department in Zhejiang Province (2015112389), the National Key Research and Development Program (2016YFC1307100, 2016YFC1307102), the Public Welfare Project of Science Technology Department of Zhejiang Province (2015C33133), the National Science and Technology Program (2015BAI13B02), and the Key Research Project of Zhejiang Province (2015C03040).

\section{Disclosure}

The authors report no conflicts of interest in this work.

\section{References}

1. Mugie SM, Benninga MA, Di Lorenzo C. Epidemiology of constipation in children and adults: a systematic review. Best Pract Res Clin Gastroenterol. 2011;25(1):3-18.

2. Rao SS, Rattanakovit K, Patcharatrakul T. Diagnosis and management of chronic constipation in adults. Nat Rev Gastroenterol Hepatol. 2016; 13(5):295-305.

3. Shin JE, Jung HK, Lee TH, et al. Guidelines for the diagnosis and treatment of chronic functional constipation in Korea, 2015 revised edition. J Neurogastroenterol Motil. 2016;22(3):383-411.

4. Wald A. Constipation: advances in diagnosis and treatment. JAMA. 2016;315(2):185-191.

5. De Hert M, Hudyana H, Dockx L, et al. Second-generation antipsychotics and constipation: a review of the literature. Eur Psychiatry. 2011; 26(1):34-44.

6. Uher R, Farmer A, Henigsberg N, et al. Adverse reactions to antidepressants. Br J Psychiatry. 2009;195(3):202-210.

7. Drubach DA. Obsessive-compulsive disorder. Continuum (Minneap Minn). 2015;21:783-788.

8. American Psychiatric Association. Diagnostic and Statistical Manual of Mental Disorders. 4th ed. Washington, DC: American Psychiatric Association; 2000:462-463. text revision.

9. Hirschtritt ME, Bloch MH, Mathews CA. Obsessive-compulsive disorder: advances in diagnosis and treatment. JAMA. 2017;317(13): 1358-1367.

10. Simpson HB, Huppert JD, Petkova E, Foa EB, Liebowitz MR. Response versus remission in obsessive-compulsive disorder. J Clin Psychiatry. 2006;67(2):269-276.

11. Goodman WK, Price LH, Rasmussen SA, et al. The Yale-Brown Obsessive-Compulsive Scale. I. Development, use, and reliability. Arch Gen Psychiatry. 1989;46(11):1006-1011.

12. Turna J, Grosman Kaplan K, Anglin R, Van Ameringen M. What's bugging the gut in OCD? A review of the gut microbiome in obsessivecompulsive disorder. Depress Anxiety. 2016;33(3):171-178.
Neuropsychiatric Disease and Treatment

\section{Publish your work in this journal}

Neuropsychiatric Disease and Treatment is an international, peerreviewed journal of clinical therapeutics and pharmacology focusing on concise rapid reporting of clinical or pre-clinical studies on a range of neuropsychiatric and neurological disorders. This journal is indexed on PubMed Central, the 'PsycINFO' database and CAS,

\section{Dovepress}

and is the official journal of The International Neuropsychiatric Association (INA). The manuscript management system is completely online and includes a very quick and fair peer-review system, which is all easy to use. Visit http://www.dovepress.com/testimonials.php to read real quotes from published authors. 